Conference Proceedings Paper

\title{
Analysis of Changes on Moisture Sources Contributions for Arctic Region in a Future Climate Scenario Using GFDL/CM3 Model
}

\author{
Luana Albertani Pampuch 1,*, Raquel Nieto 2,3, Luis Gimeno ${ }^{2}$, Tércio Ambrizzi ${ }^{3}$ \\ and Marta Vázquez ${ }^{2}$ \\ Published: 15 July 2016 \\ 1 UNESP- Univ Estadual Paulista, Campus São José dos Campos, São Jose dos Campos, Brazil \\ 2 Environmental Physics Laboratory (EPhysLab), Facultade de Ciencias, Universidad de Vigo, Ourense, \\ Spain \\ 3 USP - University of São Paulo, São Paulo, Brazil \\ * Correspondence: luana.pampuch@ict.unesp.br
}

\begin{abstract}
The IPCC Fifth Assessment Report suggests that the projected increase in the global temperature in future scenarios could cause different impacts in different regions of the world. For the Polar Regions the global models are being adapted to measure these changes, but the preliminary results indicate large heating for the Arctic region. The changes on Arctic region are not a problem just for a future climate: the Arctic amplification, the decrease on Arctic sea ice extent and on snow cover extent is a present concern for climatologists. Studies suggest a link between Arctic changes and mid-latitude weather, as the changes on Arctic Region where observed accompanied by changes in other regions of the world, especially in the Northern Hemisphere mid-latitude. Some mechanisms are proposed to explain this link, and one of then is related to changes in the atmospheric moisture transport from middle latitudes. Recent studies have shown that the Mediterranean Sea, North Atlantic Ocean and North Pacific Ocean appear as the main regions that contribute as moisture sources to the Arctic Region. The objective of this work is to use the output of GFDL/CM3 Model for 2046-2075 and 2070-2099 periods to identify the regions of the main change on moisture sources that contributes to the Arctic Region in a future scenario (RCP4.5) compared to a present climate (1980-2005). For both future periods analysed, the results suggest that the contribution for Arctic moisture by the regions located on North Atlantic Ocean, North Africa and Middle East enhanced. This may indicate an increase in moisture transport from mid-latitude to Arctic that could lead to several changes in Arctic climate: warming, decrease on sea ice extent and on snow cover.
\end{abstract}

Keywords: Moisture Transport; Arctic Region; Climate Change

\section{Introduction}

Observational and modeling studies indicate that the water cycle is affected by changes in world temperature, in this way, is expected that in a warmer planet there will be important changes on water cycle [1]. The Intergovernmental Panel on Climate Change (IPCC) on its last report (AR5) suggests that different regions of the world will present different changes, but in a general way these are alarming in relation to a possible increase on temperature, that can cause an increase in the number of extreme events (droughts, heavy rainfall events, warmer days and nights, heat waves, tornadoes, hurricanes). In particular, the Arctic Region is one to suffer the biggest expected impacts, showing changes never seen in the past decades [2]. 
The 1st International Electronic Conference on Atmospheric Sciences (ECAS 2016), 16-31 July 2016; Sciforum Electronic Conference Series, Vol. 1, 2016

The changes on Arctic climate is a concern, where extreme temperatures were registered on this century with an increase two times faster than the global average (Arctic amplification) [3]. Associated to this warming, it was also observed a decrease on Arctic sea ice extent (the largest declined rate occurred in September: 12,4\% per decade since 1979) [4]; and on snow cover extent (loss rate: 53\% from 1959 to 2000) [5].

At the same time that these changes where observed on the Arctic, other regions of the world, especially in the Northern Hemisphere mid-latitudes, showed the occurrence of extreme heat and rainfall events [3]. These facts suggest a possible link between Arctic change and mid-latitude weather. Some dynamical changes where proposed by [3] to explain this link: changes in storm tracks, weakeaning of the jet stream, and changes on configuration of the planetary waves [3].

The interpretation of the most significant observed changes in the Arctic can be related to changes in the atmospheric moisture (increased transport from middle latitudes) [6]. [7] stressed that the study of the behavior of source and sink moisture regions allows the investigatigation on how occurs the water cycle around the world. In this way, [8] used a Lagrangian analysis to determine that Mediterranean Sea, North Atlantic Ocean and North Pacific Ocean appear as the main sources moisture regions to the Arctic. Besides, a connection between the increase in evaporation over these source regions and Arctic ice melting where founded.

In a study using 22 global circulation models from the Climate Model Intercomparison Project Phase 5 (CIMP5), [9] investigate projected changes on global atmospheric water vapor transport for future scenarios, finding an increase by $30 \%-40 \%$ over the storm tracks regions located on North Pacific and North Atlantic, and in the Equatorial Pacific Ocean. In this way, changes on regions that contributes as moisture sources to the Arctic could contribute to an intensification to the Arctic amplification, decrease on Arctic sea ice and on snow cover extent.

The objective of this work is to better understand how changes in the moisture on the regions of Mediterranean Sea, North Atlantic Ocean and North Pacific Ocean affect the moisture supply in the Arctic region. To perform these analysis we used the output of GFDL/CM3 Model for two future periods (2046-2075 and 2070-2099) considering the scenario RCP4.5, and compared to the present climate (1980-2005).

\section{Experiments}

In the study of [8] were computed the contribution of each moisture source to Arctic precipitation through the series of $(E-P)<0$ using the Lagrangian Dispersion Particle Model FLEXPART (for more details see $[8,10]$ ). These series (hereafter Ps) where provided by these authors for the period 1980-2012. In this work, we only analyse the North Atlantic Ocean region (hereafter NAO) for October-March 1980-2005 (as in Gimeno et al., 2015) named present period.

Monthly vertical integrated moisture fluxes in zonal and meridional directions were calculated as in [9] using ERA Interim data [11] for the present period; and the GFDL/CM3 model [12] for the present and two future periods with RC4.5 scenario: 2046-2075 (hereafter fut1) and 2070-2099 (hereafter fut2).

We performed linear correlations (r) between Ps and VIMF in zonal (VIMFz) and meridional (VIMFm) directions using Era Interim and GFDL/CM3 for the present period. The analysis of the regions of significant correlations (90\% level) between the source (NAO) and the sink (Arctic) can provide us a better understanding about the moisture path between both. The analysis of $\mathrm{r}$ signal is important because $r>0$ indicate that an enhacend (decrease) on VIMF is associated to a enhanced (decrease) on Ps; and $r<0$ indicate that an enhacend (decrease) on VIMF is associated to a decrease (enhanced) on Ps.

A spatial mean of VIMFz and VIMFm in these regions were calculated for the present and futures periods, and the comparison of these data can show how are the changes on moisture path. 
The 1st International Electronic Conference on Atmospheric Sciences (ECAS 2016), 16-31 July 2016; Sciforum Electronic Conference Series, Vol. 1, 2016

\section{Results}

The spatial pattern of VIMFz (Figure 1) and VIMFm (Figure 2) is well represented by the model when compared to Era Interim reanalysis in the historical period (Figure 2a,b). Comparing the two future periods (Figure 2c,d), the patterns are similar and intensity do not demonstrante any significant change. For the comparison of present and future periods one can see that the pattern is similar but the intensity is modified, suggesting possible changes on global atmospheric water vapor transport in a future scenario (as founded by [9]).

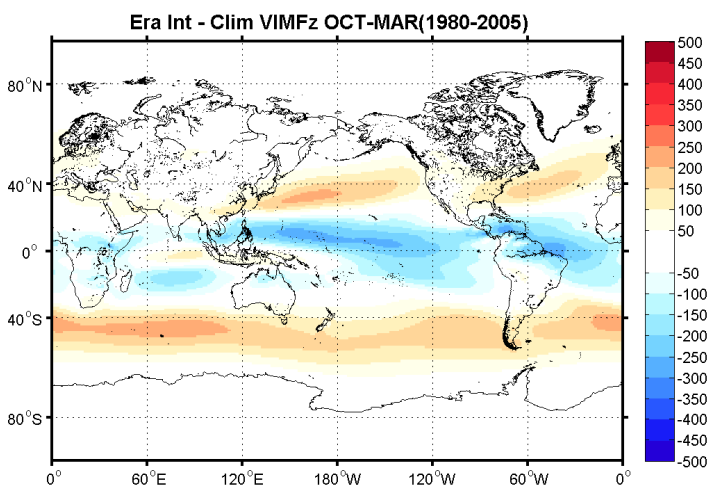

(a)

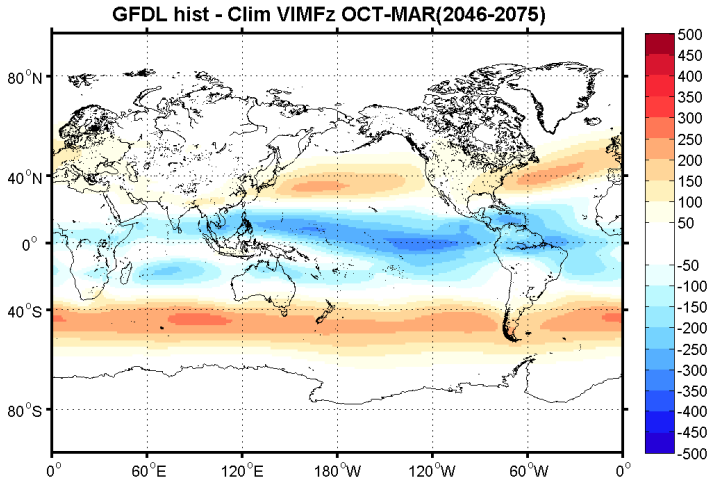

(c)

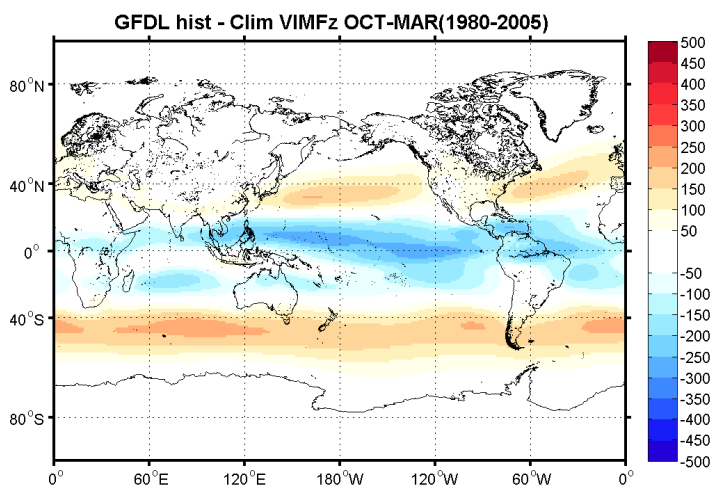

(b)

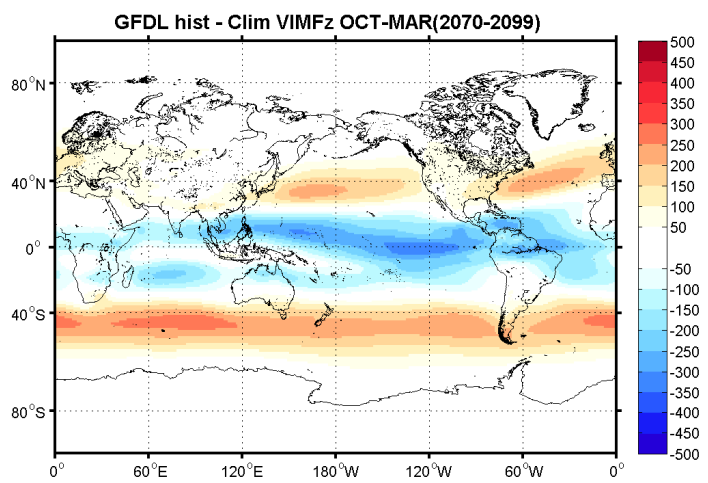

(d)

Figure 1. Vertical Integrated Moisture Fluxes (in $\mathrm{Kg} \cdot \mathrm{m}^{-1} \cdot \mathrm{s}^{-1}$ ) on zonal direction for (a) Era Interim in the present period; (b) GFDL/CM3 Model in the present period; (c) GFDL/CM3 in the fut1 period; (d) GFDL/CM3 Model in the fut2 period.

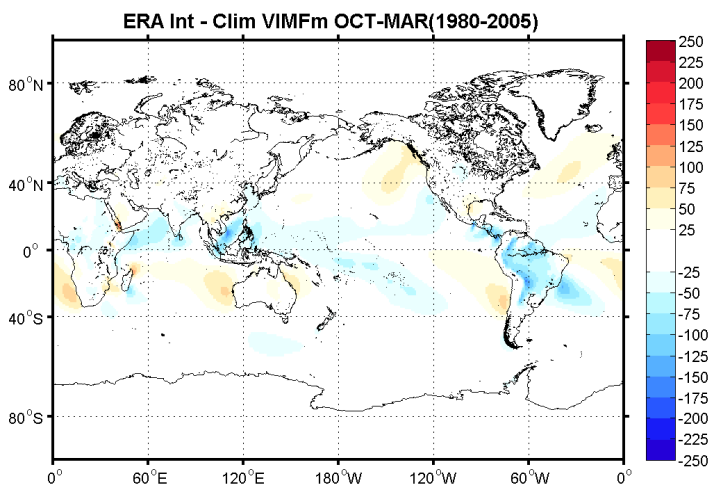

(a)

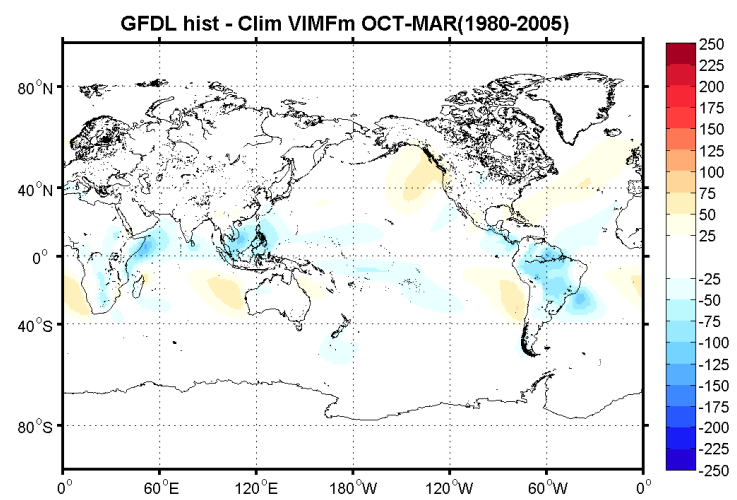

(b)

Figure 2. Cont. 
The 1st International Electronic Conference on Atmospheric Sciences (ECAS 2016), 16-31 July 2016;

Sciforum Electronic Conference Series, Vol. 1, 2016

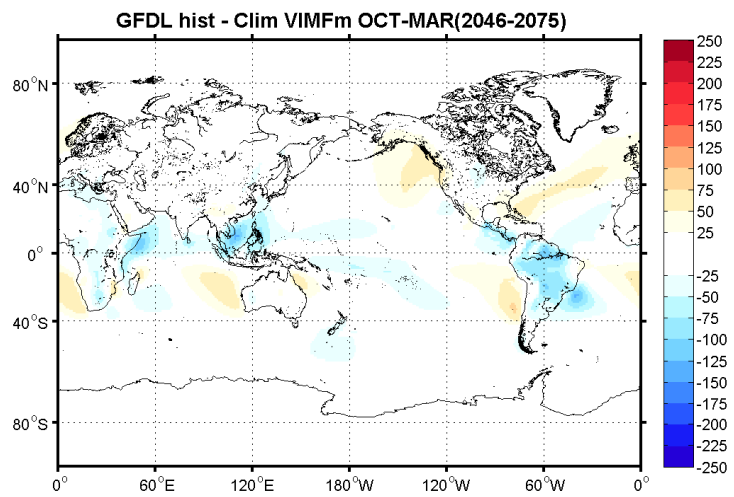

(c)

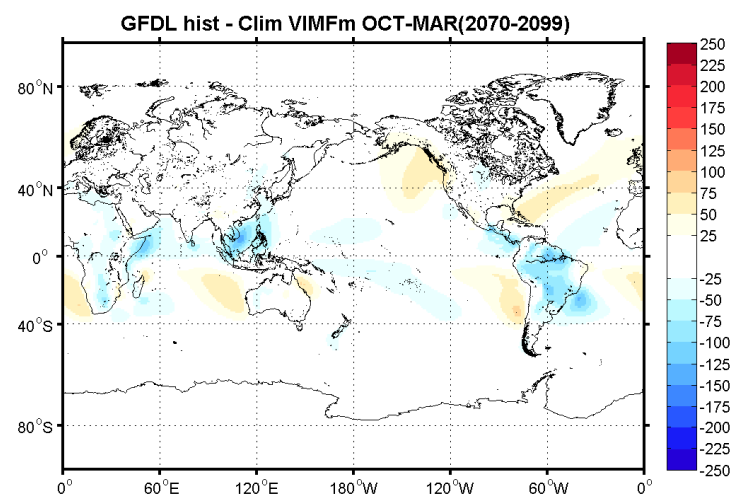

(d)

Figure 2. Vertical Integrated Moisture Fluxes (in $\mathrm{Kg} \cdot \mathrm{m}^{-1} \cdot \mathrm{s}^{-1}$ ) on meridional direction for (a) Era Interim in the present period; (b) GFDL/CM3 Model in the present period; (c) GFDL/CM3 in the fut1 period; (d) GFDL/CM3 Model in the fut2 period.

The linear significant correlation (figures not shown) provide us four regions to analyse (Figure 3): two in zonal direction (Z1:orange and Z2: purple), and two in meridional direction (M1: blue and M2: red). The value of $r$ is also indicated in Figure 3. The M1 region comprises the portion of the North Atlantic closed to Europe coast and $r=0,29$; the M2 region comprises the western portion of Europe and East Asia, with $r=-0,30$; the Z1 region comprises North Africa and $r=-0,32$; the Z2 region includes the North Atlantic Ocean on the east coast of North America, and $r=0,29$.

For each region (Z1, Z2, M1 and M2) the mean value for VIMFz and VIMFm for the present period using Era Interim and GFDL/CM3 Model and for the future periods are showed on Table 1 (in $\mathrm{Kg} \cdot \mathrm{m}^{-1} \cdot \mathrm{s}^{-1}$ ).

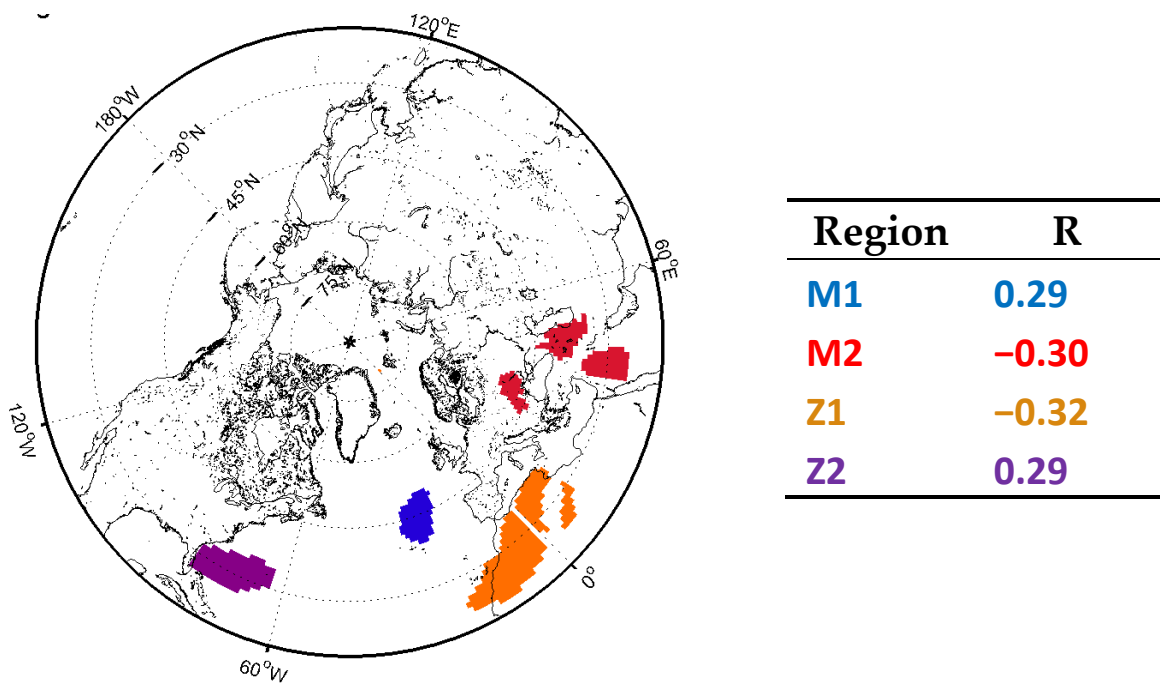

Figure 3. Selected regions (M1, M2, Z1 and Z2) with a significant correlation $(r)$ between Ps series and VIMFz and VIMFm fields for NAO source region; and $r$ values for each region. 
The 1st International Electronic Conference on Atmospheric Sciences (ECAS 2016), 16-31 July 2016; Sciforum Electronic Conference Series, Vol. 1, 2016

Table 1. Mean values for VIMFz and VIMFm (depending on the case) for selected regions for best correlations for NAO source.

\begin{tabular}{rcccc}
\hline Region & ERA Interim & GFDL/CM3 HIST & GFDL/CM3 FUT1 & GFDL/CM3 FUT2 \\
\hline M1 & 35.04 & 33.30 & 45.35 & 39.04 \\
M2 & 8.99 & 6.14 & 3.24 & 4.37 \\
Z1 & 26.76 & 9.82 & 0.099 & 4.92 \\
Z2 & 117.47 & 102.13 & 98.30 & 111.19 \\
\hline
\end{tabular}

\section{Discussion}

The analysis for each region is performed analising the $r$ signal and the behavior of VIMF in the future period compared to the present period (increase or decrease) where these results are displaced in Table 2. For M1 region the correlation is positive and there is an increase in VIMFm for the two future periods in relation to the present; for M2 region the correlation is negative and the data show a decrease in VIMFm for the two future periods in relation to the present; for Z1 region the correlation is negative and there is a decrease in VIMFz for future periods; and for Z2 region the correlation is positive and VIMFz decrease for FUT1 and increase for FUT2.

Table 2. Summary for the results founded in these analysis: $r$ signal, behavior of VIMF in the future compared to the present period (increase or decrease), and conclusion for the source region contribuition to the Arctic moisture.

\begin{tabular}{lllll}
\hline Region & r Signal & $\begin{array}{l}\text { VIMF } \\
\text { (Compared to the Present) }\end{array}$ & $\begin{array}{l}\text { VIMF } \\
\text { (Compared to the Present) }\end{array}$ & $\begin{array}{l}\text { Conclusion } \\
\text { (Source Contribution) }\end{array}$ \\
\hline M1 & + & Increases & Increases & Increase \\
M2 & - & Decreases & Decreases & Increase \\
Z1 & - & Decreases & Decreases & Increase \\
Z2 & + & Decreases & increases & Decrease/increase \\
\hline
\end{tabular}

The regions where the VIMF value increases (decreases) in the future and the correlation is positive (negative) indicates that the moisture source has a higher contribution to the sink area. The regions where the VIMF value increases (decreases) in the future and the correlation is negative (positive) suggests that the moisture source contributes less to the sink area.

In this way, for all analysed regions and for both future periods (except for Z2) the GFDL/CM3 model shows a greater contribution of the regions to the moisture sources of the Arctic. This may indicate an increase in moisture transport and as we have previously cited, a decrease of the ice.

These analyses were performed considering the NAO source region, it is intended to also expand to North Pacifi Ocean (NPO) and Mediterraneo (MED). Following the work of Lavers et. al (2015) several CMIP5 models will also be analysed .

\section{Conclusions}

In this work we investigate the behavior of the moisture source region for the Arctic, located on the North Atlantic Ocean, considering a future scenario (RCP4.5) for two different periods: 2046-2075 and 2070-2099. For these analysis we used $(E-P)<0$ series for Arctic sink region (that shows the contribution of the moisture source regions) (provided by [8]) and vertical integrated moisture fields on meridional and zonal directions to performe linear correlations. The regions in the path between the source and sink that shows best correlations provide locations to investigate changes in moisture fluxes in a future scenario. The vertical integrated moisture fluxes for future scenarios using the GFDL/CM3 model were usuful to better understand the expected changes in the climate.

For both future periods analysed, the results suggest that the regions located over North Atlantic Ocean, North Africa and Middle East, in the path between the moisture source (NAO) and the sink (Artic), occurs an increase on his contribuition for the Arctic moisture. These results may 
The 1st International Electronic Conference on Atmospheric Sciences (ECAS 2016), 16-31 July 2016; Sciforum Electronic Conference Series, Vol. 1, 2016

indicate an increase on moisture transport from mid-latitude to Arctic, that could lead to a temperature rise and significant changes (decrease) on ice extent and snow cover.

Acknowledgments: L.A. Pampuch acknowledge funding by the National Counsel of Technological and Scientific Development (CNPq) processes 150243/2015-4 and 401155/2014-5. L. Gimeno and R. Nieto acknowledge funding by the Spanish government within the EVOCAR (CGL2015-65141-R) project, which is also funded by FEDER (European Regional Development Fund). R. Nieto was also supported by the Brazilian government through the CNPq grant 314734/2014-7.

Conflicts of Interest: "The authors declare no conflict of interest." "The founding sponsors had no role in the design of the study; in the collection, analyses, or interpretation of data; in the writing of the manuscript, and in the decision to publish the results".

\section{Abbreviations}

The following abbreviations are used in this manuscript:

CIMP5: Climate Model Intercomparison Project Phase 5

FUT1: future period (2046-2075)

FUT2: future period (2070-2099)

IPCC: Intergovernmental Panel on Climate Change

MED: Mediterraneo

M1: North Atlantic closed to Europe coast (region founded for best correlation between Ps and VIMFm)

M2: western portion of Europe and East Asia (region founded for best correlation between Ps and VIMFm)

NAO: North Atlantic Ocean

NPO: North Pacific Ocean

Ps: contribution of each moisture source to Arctic precipitation through (series of $(E-P)<0$ )

r: linear coefficient correlation (Pearson)

VIMF: Vertical Integrated Moisture Flux

VIMFz: Vertical Integrated Moisture Flux on Zonal Direction

VIMFm: Vertical Integrated Moisture Flux on Meridional Direction

Z1: North Africa region (region founded for best correlation between Ps and VIMFz)

Z2: North Atlantic Ocean on the east coast of North America (region founded for best correlation between Ps and VIMFz)

\section{References}

1. Held, I.M.; Soden, B.J. Robust responses of the hydrological cycle to global warming. J. Clim. 2006, 19, 5686-5699.

2. Intergovernmental Panel on Climate Change (IPCC). 2014: Climate Change 2014: Synthesis Report. Contribution of Working Groups I, II and III to the Fifth Assessment Report of the Intergovernmental Panel on Climate Change; Core Writing Team, Pachauri, R.K., Meyer, L.A., Eds.; IPCC: Geneva, Switzerland, 2014; p. 151.

3. Cohen, J.; Screen, J.A.; Furtado, J.C.; Barlow, M.; Whittleston, D.; Coumou, D.; Francis, J.; Dethloff, K.; Entekhabi, D.; Overland, J.; et al. Recent Arctic amplification and extreme mid-latitude weather. Nat. Geosci. 2014, 7, 627-637.

4. Stroeve, J.C.; Maslanik, J.; Serreze, M.C.; Rigor, I.; Meier, W.; Fowler, C. Sea ice response to an extreme negative phase of the Arctic Oscillation during winter 2009/2010. Geophys. Res. Lett. 2011, 38, L02502.

5. Kwok, R.; Rothrock, D.A. Decline in Arctic sea ice thickness from submarine and ICESat records: 1958-2008. Geophys. Res. Lett. 2009, 36, L15501.

6. Zhang, X.; He, J.; Zhang, J.; Polyakov, I.; Gerdes, R.; Inoue, J.;Wu, P. Enhanced poleward moisture transport and amplified northern high-latitude wetting trend. Nat. Clim. Chang. 2012, 3, 47-51.

7. Gimeno, L.; Stohl, A.; Trigo, R.M.; Domínguez, F.; Yoshimura, K.; Yu, L.; Drumond, A.; Durán-Quesada, A.M.; Nieto, R. Oceanic and Terrestrial Sources of Continental Precipitation. Rev. Geophys. 2012, 50, RG4003.

8. Gimeno, L.; Vázquez, M.; Nieto, R.; Trigo, R.M. Atmospheric moisture transport: The bridge between ocean evaporation and Arctic ice melting. Earth Syst. Dynam. 2015, 6, 583-589. 
The 1st International Electronic Conference on Atmospheric Sciences (ECAS 2016), 16-31 July 2016;

Sciforum Electronic Conference Series, Vol. 1, 2016

9. Lavers, D.A.; Ralph, F.M.; Waliser, D.E.; Gershunov, A.; Dettinger, M.D. Climate change intensification of horizontal water vapor transport in CMIP5. Geophys. Res. Lett. 2015, 42, doi:10.1002/2015GL064672.

10. Stohl, A.; James, P.A. Lagrangian analysis of the atmospheric branch of the global water cycle: Part I. Method description, validation, and demonstration for the August 2002 flooding in central Europe. J. Hydrometeorol. 2004, 5, 656-678.

11. Dee, D.P.; Uppala, S.M.; Simmons, A.J.; Berrisford, P.; Poli, P.; Kobayashi, S.; Andrae, U.; Balmaseda, M.A.; Balsamo, G.; Bauer, P.; et al. The ERA-Interim reanalysis: Configuration and performance of the data assimilation system. Quart. J. Roy. Meteor. Soc. 2011, 137, 553-597.

12. Donner, L.J.; Wyman, B.L.; Hemler, R.S.; Horowitz, L.W.; Ming, Y.; Zhao,M.; Golaz, J-C.; Ginouxa, P.; Lin, S-J.; Schwarzkopf, M.D.; et al. The Dynamical Core, Physical Parameterizations, and Basic Simulation Characteristics of the Atmospheric Component AM3 of the GFDL Global Coupled Model CM3. J. Clim. 2011, 24, 3484-3519.

(C) 2016 by the authors; licensee MDPI, Basel, Switzerland. This article is an open access article distributed under the terms and conditions of the Creative Commons by Attribution (CC-BY) license (http://creativecommons.org/licenses/by/4.0/). 